This is the authors' accepted manuscript version of a book chapter. Please cite as:

Wilhelm, F., \& Hirschi, A. (2019). Career Self-Management as a Key Factor for Career Wellbeing. In I. L. Potgieter, N. Ferreira, \& M. Coetzee (Eds.), Theory, Research and Dynamics of Career Wellbeing: Becoming Fit for the Future (pp. 117-137). Springer International Publishing. https://doi.org/10.1007/978-3-030-28180-9_6

\title{
Career self-management as a key factor for career wellbeing
}

\author{
Francisco Wilhelm and Andreas Hirschi \\ Institute of Psychology, University of Bern
}

\begin{abstract}
Author Note
Correspondence concerning this article should be addressed to Francisco Wilhelm, Institute of Psychology, University of Bern, Fabrikstrasse 8, CH-3012 Bern, Switzerland (email: francisco.wilhelm@psy.unibe.ch).
\end{abstract}




\begin{abstract}
Career self-management (CSM) is an important factor for achieving career wellbeing and is becoming increasingly crucial in career environments characterized by higher volatility, uncertainty, complexity, and ambiguity. In this chapter, we provide an overview of current research on CSM, and conceptually and empirically clarify its relation to career wellbeing. First, we define CSM and delineate its dimensionality. Second, we concisely summarize the empirical research on predictors and career wellbeing related outcomes of CSM. Third, based on our literature review, we suggest how CSM can be promoted through interventions, and how organizations can create synergies between organizational and individual career management. Finally, we suggest avenues for further research addressing identified research gaps: conceptual refinement, investigating facilitators of CSM at different action stages, broadening the scope of investigated career wellbeing outcomes of CSM, conducting theory-based intervention studies to systematically promote CSM, and examining contextual influences emerging in Industry 4.0 worklife spaces.
\end{abstract}




\section{Career self-management as a key factor for career wellbeing}

The fourth industrial revolution is predicted to increase the volatility, uncertainty, ambiguity, and complexity of career environments for workers across the skill spectrum. In the coming decades, we can expect to see the elimination of many jobs and fundamental changes to the skill requirements of many occupations (International Labour Organization, 2018). For example, a recent report by the World Economic forum predicts that around half of the global workforce will require major re- or upskilling by 2022 (World Economic Forum, 2018). Furthermore, the traditional employment model of stable full-time employment within a single organization is receding as a result of new employment types, such as gig work (Ashford, Caza, \& Reid, 2018), shifting responsibility for career management from organizations to individuals. These changes are likely to result in growing job, occupational and career insecurity, especially when workers are left to face these changes unprepared. Therefore, it seems clear that the fourth industrial revolution is a potential threat to the career wellbeing of workers (Hirschi, 2018).

One aspect of the solution to this problem emphasizes strengthening the capabilities of individuals for career self-management (CSM). Through CSM, it is argued, workers are enabled to adapt to the upcoming transformations in a way that serves both their own goals and those of the economy (e.g., Lent, 2018). This argument is backed up by several studies and meta-analyses pointing out the potential of facets of CSM (e.g., continuous learning, networking) for enhancing career wellbeing (e.g., Fuller \& Marler, 2009; Ng, Eby, Sorensen, \& Feldman, 2005). In our chapter we refer to career wellbeing broadly, as the various positive outcomes associated with successful career development across the lifespan. Furthermore, the need for building the capabilities for CSM and lifelong learning of the workforce is recognized on the policy level across many Western 
states (e.g., Commission of the European Communities, 2003; Hooley, Watts, Sultana, \& Neary, 2013). In sum, CSM can be a powerful contributor to career wellbeing amidst the complexities of career environments in Industry 4.0.

Despite the high value put on CSM in theoretical works and at the policy level, the current academic literature on CSM has several shortcomings. Foremost, there is a striking lack of integration of empirical research on the topic. As such, the literature is heterogeneous, with little agreement on how to define or measure the construct, and inconsistencies between findings. In this chapter, we seek to address these issues. In the following section, we first define CSM and delineate the dimensionality of the construct. Second, we summarize the empirical research on predictors and well-being related outcomes of CSM. Based on these steps, we suggest how CSM can be enhanced through career counseling, and how organizations can achieve a synergy between organizational career management and individual career management. Finally, we suggest avenues for further research that could advance our understanding of the interrelations among CSM, shifts in the structure of career environments, and career wellbeing.

\section{Conceptual clarification}

\section{Defining the construct}

There are numerous definitions of CSM. Greenhaus, Callanan, and Godshalk (2010) define career (self-)management ${ }^{1}$ as "a process by which individuals develop, implement, and monitor career goals and strategies" (p. 12). Another highly cited framework describes CSM as a

\footnotetext{
${ }^{1}$ Because we want to distinguish career management by the individual from career management by the organization, we prefer the term career self-management (CSM) to denote the former, and refer to the latter as organizational career management.
} 
"dynamic process, involving execution of a set of co-occurring behaviors (...) that is intended to prevail upon the decisions made by those gatekeepers who are in a position to influence (...) desired career outcomes" (King, 2004, p. 119). These definitions highlight several core aspects of the construct which we will now unravel.

First, based on existing frameworks, we conceptualize CSM as a process of action regulation (Raabe, Frese, \& Beehr, 2007) and resource management (Hirschi, 2012). We thus propose that CSM is a process of intentionally building, maintaining, and using various personal and contextual resources through processes such as goal setting, mapping the environment for resources, planning, monitoring actions, and feedback-processing in a way that leads to positive career outcomes (Spurk, Hirschi, \& Dries, 2018). This process can range from a highly conscious, proactive, integrated process of setting, executing, and regulating goals pursuits in a strategic and wellplanned manner, to a more reactive, loosely integrated process that occurs more or less improvised as a response to external cues and events (King, 2004). Second, it is the individual, not the organization or another entity, that ultimately generates and regulates this process. Therefore, CSM puts heavy emphasis on personal agency. Third, CSM focusses on behavior, rather than attitudes, abilities, or other psychological aspects. Such psychosocial constructs and abilities are closely related to CSM but should theoretically be seen as predictors or outcomes of CSM, rather than its core components.

As a corollary to the focus on behavior and the varying degree of integration of these behaviors into a process, CSM behaviors are conceptualized as co-occurring and interdependent, rather than isolated and independent from each other. It follows that CSM research is not only interested in the relation between CSM and its antecedents and outcomes, but also in the internal relations between different kinds of CSM behaviors by which these form a process. 
Furthermore, we posit that CSM can be used by people for a variety of goals extending beyond the sphere of traditional norms of career success. In contrast to preceding constructs such as career strategies, defined as "strategies or methods which might be employed to hasten the achievement of upward mobility and salary progression" (Gould \& Penley, 1984, p. 244), our definition of CSM thus acknowledges the plurality of meanings careers can have for persons, and the diversity of roles careers play in relation to other life domains. These multiple goals need to be reflected when considering which types of behaviors can be considered CSM behaviors.

\section{Types of behavior considered CSM behavior}

\section{---- INSERT TABLE 1 HERE ----}

Since CSM is a construct with a behavioral focus, it is of critical interest to delineate which types of behavior can be considered CSM behavior. Table 1 lists a synthesis of the types of behaviors discussed in the literature. We propose that CSM behaviors can belong into one of three categories, according to its direction: (1) behavior that is directed at applying, maintaining, or developing personal resources, such as investment in human capital, (2) behavior that is directed at applying, maintaining, or developing contextual resources, such as networking, or (3) metabehavior directed at the regulation of the CSM process, including regulation of the boundaries between work and other life domains.

Furthermore, we have added examples of measures that assess these behaviors. While many studies have relied on composite measures of CSM, either aggregating scores over multidimensional CSM scales (such as the Career Strategies Inventory, Gould \& Penley, 1984) or employing unidimensional scales of general CSM (Hirschi, Freund, \& Herrmann, 2013) there are 
often good reasons to measure individual CSM behaviors separately. Although never examined systematically, previous studies indicated that intercorrelations between individual CSM behaviors are not high enough to consider them unidimensional (e.g., Sturges, Guest, Conway, \& Davey, 2002); in addition, both theory and empirical results point out different types of CSM behavior have different relations with third variables (e.g., Claes \& Ruiz-Quintanilla, 1998; Gould \& Penley, 1984).

\section{Examining the Evidence: Antecedents and Career Wellbeing Outcomes of CSM} ---- insert FIGURE 1 HERE ----

Figure 1 shows an overview of the reviewed constructs in this chapter. We will first summarize the research on personal and contextual antecedents of CSM, and then continue with the wellbeing outcomes of CSM.

\section{Personal Antecedents of CSM}

Personality traits. A number of studies have investigated the relation between personality and CSM. It seems that that the effect of personality (e.g., the Big Five traits) on different CSM behavior is mediated through more proximate variables such as self-efficacy and outcome expectations. Most attention in the literature has been devoted to conscientiousness. Studies applying social cognitive career theory show largely that conscientiousness positively predicts CSM behavior mediated through self-efficacy, outcome expectations, and social support (Lent, Ezeofor, Morrison, Penn, \& Ireland, 2016; Lent, Morris, Penn, \& Ireland, 2018; Lim, Lent, \& Penn, 2016). A study of US undergraduates has shown how extraversion and neuroticism influence CSM process through affect: extraversion facilitated the CSM process through increasing positive affect, 
which in turn was positively related to self-efficacy and outcome expectations. Conversely, neuroticism impeded the CSM process through increasing negative affect, which in turn was negatively related to self-efficacy and outcome expectations (Ireland \& Lent, 2018).

Apart from the Big Five, functional personality constructs such as hope (Hirschi, 2014) and proactive personality have also been studied. Proactive personality has received strong support as an antecedent of CSM by meta-analytic (Fuller \& Marler, 2009) and longitudinal studies (Hirschi, Lee, Porfeli, \& Vondracek, 2013; Ok \& Vandenberghe, 2016). However, meta-analytic results of proactive personality as an antecedent of networking have been inconsistent (Thomas, Whitman, \& Viswesvaran, 2010), indicating that proactive personality does not predict all CSM facets equally. Moreover, research suggests that the effects of proactive personality on CSM are mediated through variables such as occupational self-efficacy (Hirschi, Lee, et al., 2013), protean career orientation (Herrmann, Hirschi, \& Baruch, 2015) and career resilience (Chiaburu, Baker, \& Pitariu, 2006).

Overall, research often shows that different personality traits relate to different CSM behaviors (Guthrie, Coate, \& Schwoerer, 1998). Future research should thus investigate further which traits are the most important antecedents of specific CSM behaviors. Recent developments also suggest that the relation between personality constructs and career behavior is more complex, with moderating effects of situational cues and mindsets (Heslin, Keating, \& Minbashian, 2018).

Motivational states. Several studies addressed attitudinal and emotional variables as the motivational foundation to engage in CSM. Following the model of proactive motivation (Parker, Bindl, \& Strauss, 2010), these can be classified as "can do", "reason to", and "energized to" motivational states. Within the "can do" group of motivational states, self-efficacy has received the strongest support as an antecedent of CSM behavior, both conceptualized in accordance with social 
cognitive theory (Bandura, 2001) as an expectancy for a specific behavioral domain (e.g., Hirschi, Lee, et al., 2013; Kim, Kim, \& Lee, 2019; Lent et al., 2018) or as more domain-free, general construct (Zikic \& Klehe, 2006).

Constructs such as values and goals which refer to content of motivation, or the "reason to" motivation to engage in CSM have also been studied. Positive outcome expectations, that is, the expectation that engaging in CSM will have positive consequences for one's career, have received mixed support as an antecedent of CSM in recent studies with college students and job seekers (e.g., Lent et al., 2018; Lim et al., 2016). Moreover, career orientations may provide reasons to engage in CSM. In this regard, career calling (Creed, Kjoelaas, \& Hood, 2016), as well as protean or boundaryless career orientation (Wiernik \& Kostal, in press), have been associated with increased CSM behavior. In a study of Greek graduates, a traditional career orientation with an eye towards internal promotion was related to stronger CSM (Mihail, 2008). Other studies looked at differences in the extent to which motivation for CSM behavior is experienced as autonomous, rather than controlled, seem to impact CSM, with autonomous goals showing a positive relation to CSM behavior (Hirschi, Lee, et al., 2013). Finally, a person's future work self, that is, the selfconcept of hopes and aspirations for future work life (Strauss, Griffin, \& Parker, 2012), may provide motivation for engaging in CSM and has been positively associated with CSM behaviors (Taber \& Blankemeyer, 2015).

Relatively few studies have examined "hot" affect-related motivational states as antecedents of CSM, although theoretically this "energized to" motivational component of proactive behaviors is important to consider in relation to CSM (Parker et al., 2010). Positive affect regarding ones future career seems to increase engagement in CSM (Hirschi, Lee, et al., 2013). Positive trait affectivity can increase CSM self-efficacy and outcome expectations, while negative trait affect seems to 
reduce CSM self-efficacy and has a mixed relation to outcome expectations (Ireland \& Lent, 2018; Lent, Ireland, Penn, Morris, \& Sappington, 2017). Within-person differences in positive, but not negative, affect have also shown a positive relation to CSM (Hirschi \& Freund, 2014). The matter is made more complex when focusing on CSM as an action regulation process, with affect having different functions for different stages in the process. It seems that high-activation pleasant affect (e.g., excited, enthusiastic) increases execution of CSM behavior, whereas low-activation pleasant affect (e.g., serene, relaxed) has no effect (Bindl, Parker, Totterdell, \& Hagger-Johnson, 2012). Furthermore, low-activation negative affect (e.g., sad, fatigued) may lead persons to deliberate more on their careers, but does not translate into concrete planning or execution (Bindl et al., 2012). This is line with theory and experimental evidence which shows that emotions modulate goal regulation processes (Achtziger \& Gollwitzer, 2018; Maglio, Gollwitzer, \& Oettingen, 2014).

Overall, a range of "can do", "reason to", and "energized to" motivational states seem to influence CSM. Future studies should try to replicate these findings and employ integrative models of motivation, such as the motivational model of proactivity (Parker et al., 2010), when examining the role of motivational antecedents of CSM.

\section{Contextual Antecedents of CSM}

Social support. Among contextual variables that can facilitate CSM, most attention has been given to social support. In cross-sectional studies, social support has received corroboration as a predictor of a range of CSM components such as career exploration (Lent et al., 2016), composite measures of CSM behavior (Moon \& Choi, 2017; Noe, 1996), and career exploration and planning in unemployed job seekers (Zikic \& Klehe, 2006). The positive relation between social support and CSM seems to generally be consistent across different sources of interpersonal support, 
including peers, family, coworkers, coaches (Huang \& Hsieh, 2015) and mentors (Godshalk \& Sosik, 2003).

Organizational support. Organizational support, which has been studied both as the general support of the employee (e.g., caring about the wellbeing of the employee) and more specifically as the support for the employee's career development (e.g., offering career training), seems to have a complex relation to CSM, for at least three reasons. First, organizational support and CSM form a reciprocal relation. CSM behaviors, such as networking and guidance seeking, establish support, for example by building positive relations with important gatekeepers in the organization, which in turn may further increase CSM behaviors (Sturges, Conway, Guest, \& Liefooghe, 2005; Sturges et al., 2002). Second, the effect of organizational support on CSM seems to be moderated by personal attributes such as gender and locus of control (Sturges, Conway, \& Liefooghe, 2010). For example, studies report that external locus of control reduces sensitivity to positive reinforcement (Ng, Sorensen, \& Eby, 2006), which may reduce the facilitating effect of organizational support for CSM. Third, macro-contextual variables may influence the relation between CSM and organizational career management through differences in career deals. Contemporary career deals, more common in countries with less regulated labor markets, show a "virtuous circle" between CSM and organizational career management, whereas traditional career deals in countries characterized by more regulated labor markets, organizational career management may increase organizational commitment but not CSM (Sturges, Conway, \& Liefooghe, 2008).

Barriers. Perceived barriers (e.g., disapproval of one's career path by significant others, lack of developmental opportunities in one's career field) may hinder persons from effectively engaging in CSM. The evidence for this is mixed, however, with studies showing a small positive or no effect (Hirschi \& Freund, 2014; Hirschi, Lee, et al., 2013). It is plausible that the effect of barriers 
on behavior rests on their appraisal in terms of likelihood of success (Brehm \& Self, 1989), with barriers appraised as manageable signaling the need to invest more effort, while barriers appraised as insurmountable could lead to disengagement. Hence, future studies could test whether selfefficacy interacts with barriers in predicting CSM.

Macro-context. At a macro-level, national culture predicted CSM behaviors in a comparison of six Western countries, showing, for example, that cultures high on masculinity (vs. femininity) showed less social CSM behavior, but also less skill development (Claes \& Ruiz-Quintanilla, 1998). Future studies might test whether these relations still hold 20 years later, examine other cultural values, or model culture as a moderator linking personal factors and CSM rather than treat culture as a direct predictor of CSM.

The structure of labor markets affect how easy it is for individuals to move between organizations, jobs, and occupations (Ng, Sorensen, Eby, \& Feldman, 2007), likely resulting in differential opportunities and perceived utilities for engaging in CSM. Research suggests that CSM may be more prevalent in contexts where it is easy to "hire and fire" employees, but less so in contexts with more traditional employment relations (Sturges et al., 2008). However, macro-contextual variables have received sparse attention and merit further study in order to situate research on CSM within the complexities of social environments.

\section{Career Wellbeing as an Outcome of CSM}

A number of studies support the notion that CSM is positively related to career wellbeing (Quigley \& Tymon, 2006; Spurk et al., 2018). As mentioned before, we refer to career wellbeing broadly, as the various subjective and objective positive outcomes associated with successful career development across the lifespan. The subjective side of career wellbeing refers to the personal 
experiences of individuals, reflected by constructs such as career or life satisfaction, whereas the objective side of career wellbeing refers to objective indicators such as salary level, number of promotions, and health. The relation of CSM to career wellbeing can be explained in the way that CSM builds resources such as networks (Forret, 2018), mentors (Singh, Ragins, \& Tharenou, 2009), or career goal clarity which in turn result in higher career wellbeing (Ng et al., 2005; $\mathrm{Ng} \&$ Feldman, 2014). In this chapter, we focus on outcomes at the individual level and exclude outcomes at the organizational and societal level. Although CSM may prove beneficial to organizations by boosting organizational commitment (e.g., Sturges et al., 2002), psychological contract fulfillment (Sturges et al., 2005), or performance, there is little research in this area.

Cross-sectional studies consistently support the relation between CSM and subjective indicators of career wellbeing, such as career satisfaction (e.g., Abele \& Wiese, 2008; De Vos, Dewettinck, \& Buyens, 2009; Seibert, Kraimer, \& Crant, 2001), work engagement (De Vos \& Segers, 2013), and thriving (Porath, Spreitzer, Gibson, \& Garnett, 2012). Studies examining the relation between CSM and subjective indicators of career wellbeing in a longitudinal design are still sparse, but have so far generated inconsistent results (Raabe et al., 2007; Vos, Clippeleer, \& Dewilde, 2009). These inconsistencies may be due to differences in time-lags between CSM and career wellbeing measurements. A number of studies also looked at whether different facets of CSM are of different importance to different indicators of career wellbeing (Aryee \& Debrah, 1993; Chang Boon Lee, 2002; Nabi, 1999), but evidence in this regard is too limited to draw any inferences.

The positive relation between CSM and objective indicators of career wellbeing such as salary and leadership position is supported by both cross-sectional associations (Abele \& Wiese, 2008; Smale et al., 2018; Tharenou \& Terry, 1998), and longitudinal increases regarding salary (Raabe et al., 2007) and number of promotions (Seibert et al., 2001). A study of Sri Lankan migrants to New 
Zealand has found that CSM predicts subjective and objective career success over and above both human capital and social integration (Tharmaseelan, Inkson, \& Carr, 2010). However, not every study has found an association between CSM and objective indicators of career wellbeing (e.g., De Vos et al., 2009).

Apart from more traditional subjective and objective indicators of career wellbeing, CSM seems to be beneficial for a number of outcomes rising in importance in a globalized world and a shift towards a knowledge economy; furthermore, CSM may be of specific importance for special populations such as migrants. CSM was associated with life satisfaction in a study of first year university students (Praskova, Creed, \& Hood, 2015), suggesting that CSM has effects on wellbeing beyond the career domain. Engaging in CSM may carry special significance in the transition from school to work. CSM has been shown to be associated with perceived employability of graduates both in the UK and Australia (Jackson \& Wilton, 2017b, 2017a; OkaySomerville \& Scholarios, 2017), and was more important than social background and human capital variables in predicting the perceived employability of UK graduates (Okay-Somerville \& Scholarios, 2017). CSM may also be important in proactively coping with job and career insecurity as well as job loss (Shoss, Jiang, Jundt, Lavigne, \& Probst, 2017). Studies of unemployed jobseekers indicate that CSM can increase the likelihood as well as the quality of reemployment (e.g., Zikic \& Klehe, 2006), but it has to our knowledge not been studied whether CSM is similarly helpful in coping with job and career insecurity. Finally, CSM may be of high value for older employees in dealing with challenges such as outdated skills or shifting career preferences (Kanfer \& Ackerman, 2004). However, to our best knowledge this is a topic that has received little attention. 
Negative (side) effects of CSM have been rarely studied. According to a qualitative study of UK professionals some CSM behaviors, such as extended work involvement, may lead to a prioritization of the work domain that leave little resources for other valued life goals and can hence put a strain on other life domains (Sturges, 2008). As one interviewee describing his CSM strategy put it: "it's a marriage wrecker, really" (p. 126). The lack of studies on negative effects of CSM is a major gap in the literature and we discuss possible research directions on the issue further below.

In sum, the majority of studies support the assumption that CSM leads to increased career wellbeing. Several limitations, however, need to be addressed by further studies: Most studies are cross-sectional in nature, lack a differentiated measurement of CSM and career wellbeing outcomes, with a particular negligence of the potential negative effects of CSM.

\section{Implications for Practice}

\section{Supporting Career Self-Management Through Career Guidance and Counseling}

As this review shows, CSM is not achieved through becoming a perfectly self-sufficient "free agent". To the contrary, social support is key to career agency. Career counseling can thus be a crucial means to empower people in their CSM. Given our understanding of CSM as an action regulation process and the literature reviewed above, we now make several recommendations along that line.

Since autonomous goals have been shown to predict CSM (Hirschi, Lee, et al., 2013) and are known to enhance wellbeing (Sheldon, 2014; Sheldon, Kasser, Smith, \& Share, 2002), counselors can assist clients in clarifying their personal values (Dahl, 2015) and setting self-concordant goals (Sheldon et al., 2002). Here, interventions from action regulation literature, such as mental 
contrasting (Oettingen, Schnetter, \& Pak, 2001) and implementation intention setting (Gollwitzer, Mayer, Frick, \& Oettingen, 2018), can facilitate developing, monitoring and implementing career plans. When creating plans, it is also beneficial for the client to develop a realistic assessment of barriers, and strategies to deal with these barriers. This is likely to result in the perception of barriers as manageable challenges, which could improve motivation for CSM (Hirschi, Lee, et al., 2013). Successfully managing these barriers in turn can raise self-efficacy and outcome expectations, which are key predictors of CSM. Furthermore, clients should be encouraged to build social support through behaviors such as networking and feedback-seeking. When plans have been implemented, or turn out to be unfeasible, counselors can assist in monitoring and feedback processing of the CSM process. In sum, career counselors can facilitate the CSM process of their clients and thereby prepare them for the challenges of a complex and volatile career environment.

\section{Creating Synergies Between Career Self-Management and Organizational Career Management}

Organizations are often concerned that if they encourage CSM, it will weaken the ties between the organization and the employee, resulting in reduced commitment or even turnover. Yet research suggests that the impact of CSM on organizations can be quite positive, depending on the way in which organization shape this process (Kraimer, Seibert, Wayne, Liden, \& Bravo, 2011). In this section we propose some recommendations how organizations can go about creating a career environment that results in a synergy between organizational career management and CSM, establishing a win-win situation for employee and employer.

Organizational career management can empower employees to be agents of their careers, while benefiting from the enhanced agentic capabilities of their employees. This is unlikely to be 
achieved by closely managing staff and imposing one-size-fits-all career paths that may not suit the diversity of career goals employees hold. Rather, it requires organizational support for career development that empowers the agentic capacities of employees for self-management and proactive generation of career opportunities within the organization. This can be achieved through means such as mentoring, developmental feedback, or career workshops, turning the relation of managing of the career between employee and employer into a "joint responsibility" (Orpen, 1994). There are two components crucial to success in achieving such a synergy. First, when organizations set the expectation that employees are responsible for their career management, organizations need to provide enabling career development support that is integrated into the organizational culture. An intervention study by Kossek, Roberts, Fisher, and Demarr (1998) suggests that if CSMdirected development practices are executed isolated from the organizational culture, employees may engage in less CSM. From a social exchange theory perspective, employees will react to CSM interventions and organizational career practices with different expectations towards the organizations. Indeed, people with higher CSM have higher expectations towards organizational career management (De Vos et al., 2009). Second, organizations need to provide individualized career opportunities. If organizations provide organizational support for career development but no career opportunities, they risk employee turnover (Kraimer et al., 2011). This opportunity structure does not need to take the form of traditional career ladders characterized by hierarchical, upward progression. Instead, organization and employees co-develop career opportunities within and across job roles in order to enhance workers' employability in a fast-paced knowledge economy.

Taking this empowering role towards employees will benefit organizations and employees in several ways. Meeting the individual expectations and needs of their employees, studies suggest, 
results in fulfilling psychological contracts, increased organizational commitment, and increased work performance (Kraimer et al., 2011; Sturges et al., 2005, 2002). Organizations, in turn, reduce their reliance on inflexible career structures ill-suited to fast-paced business environments and achieve higher productivity, a workforce more capable in dealing with change, and possibly, employees taking more proactive stances in other areas within the organization.

In sum, organizations should implement a form of organizational career management that empowers their employees to be proactive in managing their careers. This rests on career development practices that do not exist as isolated elements, but are integrated into continuous forms of career support and a fitting opportunity structure. If these conditions are met, a synergy that boosts both organizational capabilities and employees career wellbeing will likely result.

\section{Future Research Directions}

\section{Conceptual Refinement and Facilitators of CSM}

Future research may benefit from a more fine-grained analysis of the action process underlying CSM. Previous frameworks and research on CSM often have used what has been called a continuum model of behavior (for a discussion of this classification, see Schwarzer, 2008). In models of this type, the likelihood to engage in a behavior is seen as a continuous function of a single set of predictors. Action regulation perspectives, on the other hand, posit stage models of behavior (Achtziger \& Gollwitzer, 2018; Lord, Diefendorff, Schmidt, \& Hall, 2009). In such models, individuals must pass through different stages before engaging in a behavior, such as developing and setting goals, mapping the environment for goal-facilitating resources, and planning for goal attainment. Different models propose different stages, but they usually feature a 
stage in which a goal or intention is formed and a volitional stage in which behaviors to pursue the goal are executed.

By analytically distinguishing between such action regulation stages, future research may generate better insights into the process dynamics of CSM. An important avenue is the exploration of facilitators of CSM at different stages of action regulation. For example, future research could explore which factors facilitate goal setting and lead to adequacy of these goals in terms of fit with personal values and available resources (Greenhaus, Callanan, \& Kaplan, 1995); another pertinent question is which facilitators help to overcome "intention-behavior gaps" relating to CSM. Ultimately, such research could greatly benefit interventions, making it possible to tailor interventions to motivational stages.

\section{Broadening the Scope of Investigated Career Wellbeing Outcomes of CSM}

A large majority of studies we reviewed has focused on wellbeing outcomes of CSM in terms of success and satisfaction. We propose that future research pays more attention to two aspects of potential career wellbeing outcomes of CSM: (1) the potential negative side of high engagement in CSM, and (2) eudemonic and whole-life perspectives of career wellbeing.

The near future will see a workforce that is at the same time growing older and needs to stay continuously up-to-date. This calls for greater attention to the long-term sustainability of careers (De Vos, Van der Heijden, \& Akkermans, 2018). In this regard, CSM can be double-edged. Related theory and research on proactivity has shown that proactive behavior, which CSM can be seen as a special kind of, can lead to resource loss and exhaustion resulting from continuous resource investment (Cangiano \& Parker, 2015). Such effects seem particularly likely if proactive behavior is driven by controlled motivation rather than autonomous motivation (e.g., Strauss, Parker, \& 
O'Shea, 2017), or if the social context is unsupportive (Zacher, Schmitt, Jimmieson, \& Rudolph, 2018). Hence, future research could examine under which conditions CSM becomes unsustainable in the long-term, potentially leading to burnout and other negative career wellbeing outcomes. Furthermore, future studies should broaden the scope of positive outcomes of CSM, such as career wellbeing from a eudemonic angle. For example, CSM may lead to the satisfaction of intrinsic needs of mastery, relatedness, and autonomy (Ryan \& Deci, 2000), as well as higher levels of functioning (Vittersø, 2013). Second, CSM may also have implications for outcomes at the worknonwork interface, such as achieving work-family balance, that could be considered in future research. Research also suggests that career wellbeing may not only be an endpoint to CSM, but can also be a resource that spurs further CSM; hence, future studies could study wellbeing also an antecedent of engagement in CSM and test whether wellbeing and CSM are reciprocally related (Spurk et al., 2018).

\section{Conducting Theory-Based Intervention Studies}

Current research is mostly observational. Our literature search identified only three intervention studies (Buunk, Peiró, \& Griffioen, 2007; Kossek et al., 1998; Raabe et al., 2007). We thus encourage future research that conducts theory-based intervention studies. These serve two purposes: (1) To develop better interventions and translate theories into practice, and (2) to test theories and hypotheses experimentally. One possible avenue is to conduct micro-interventions that have a solid theoretical base and allow to test which component of an intervention is effective in a way proposed by theory. This approach towards intervention and theory development has for example been successfully used in Acceptance and Commitment Therapy (Hayes, Luoma, Bond, Masuda, \& Lillis, 2006). 


\section{Examining Emerging Contextual Influences}

The fourth industrial revolution will further increase the trends towards the pluralization of lifestyles, working arrangements, and career trajectories (Spreitzer, Cameron, \& Garrett, 2017). Furthermore, the workforce may see a polarization in terms of high-skilled and well-paid work as well as various forms of low-skilled, precarious work (Hirschi, 2018). These trends pose new challenges for CSM research. CSM will likely become a necessity for most workers, but the respective implications for CSM are different. For high-skilled workers, CSM may help selecting autonomous goals (D. T. Hall, Yip, \& Doiron, 2018) and achieving effective boundary management (Hirschi, Shockley, \& Zacher, 2018), whereas for disadvantaged workers CSM may help in securing decent work (Duffy, Blustein, Diemer, \& Autin, 2016; Ghai, 2003). Therefore, we encourage future studies to measure the context in which persons employ CSM in greater detail. Previous research has been too negligent in measuring these contexts, and has produced largely context-free models and research. Studying the boundary conditions under which different facets of CSM are effective in attaining career wellbeing will be an important contribution to theory and practice.

\section{Conclusion}

In this chapter, we hope to have shown the potential of CSM research for gaining an understanding of the mechanisms through which we can prepare the current and future generations of the workforce for a "future-fit" form of career wellbeing. The field of CSM shows much promise, but is also still in its early stages. Through our synthesis of the current state of 
research we hope we can move the field forward into promising new directions that will keep it relevant for the challenges posed by the fourth industrial revolution.

\section{References}

Abele, A. E., \& Wiese, B. S. (2008). The nomological network of self-management strategies and career success. Journal of Occupational and Organizational Psychology, 81(4), 733-749. https://doi.org/10.1348/096317907X256726

Achtziger, A., \& Gollwitzer, P. M. (2018). Motivation and volition in the course of action. In J. Heckhausen \& H. Heckhausen (Eds.), Motivation and action (pp. 485-527). Springer.

Aryee, S., \& Debrah, Y. A. (1993). A cross-cultural application of a career planning model. Journal of Organizational Behavior, 14(2), 119-127. https://doi.org/10.1002/job.4030140203

Ashford, S. J., Caza, B. B., \& Reid, E. M. (2018). From surviving to thriving in the gig economy: A research agenda for individuals in the new world of work. Research in Organizational Behavior. https://doi.org/10.1016/j.riob.2018.11.001

Bandura, A. (2001). Social Cognitive Theory: An Agentic Perspective. Annual Review of Psychology, 52(1), 1-26. https://doi.org/10.1146/annurev.psych.52.1.1

Bindl, U. K., Parker, S. K., Totterdell, P., \& Hagger-Johnson, G. (2012). Fuel of the self-starter: How mood relates to proactive goal regulation. Journal of Applied Psychology, 97(1), 134150. https://doi.org/10.1037/a0024368

Brehm, J. W., \& Self, E. A. (1989). The Intensity of Motivation. Annual Review of Psychology, 40(1), 109-131. https://doi.org/10.1146/annurev.ps.40.020189.000545

Buunk, A. P., Peiró, J. M., \& Griffioen, C. (2007). A Positive Role Model May Stimulate CareerOriented Behavior. Journal of Applied Social Psychology, 37(7), 1489-1500. https://doi.org/10.1111/j.1559-1816.2007.00223.x

Cangiano, F., \& Parker, S. K. (2015). Proactivity for Mental Health and Well-Being. In S. Clarke, T. M. Probst, F. Guldenmund, \& J. Passmore (Eds.), The Wiley Blackwell Handbook of the Psychology of Occupational Safety and Workplace Health (pp. 228-250). John Wiley \& Sons.

Chang Boon Lee, P. (2002). Career goals and career management strategy among information technology professionals. Career Development International, 7(1), 6-13. https://doi.org/10.1108/13620430210414829

Chiaburu, D. S., Baker, V. L., \& Pitariu, A. H. (2006). Beyond being proactive: what (else) matters for career self-management behaviors? Career Development International, 11(7), 619-632. https://doi.org/10.1108/13620430610713481 
Claes, R., \& Ruiz-Quintanilla, S. A. (1998). Influences of Early Career Experiences, Occupational Group, and National Culture on Proactive Career Behavior. Journal of Vocational Behavior, 52(3), 357-378. https://doi.org/10.1006/jvbe.1997.1626

Commission of the European Communities. (2003). Human Capital in a Global and Knowledge Based Society [Final Report]. Luxembourg: Office for Official Publications of the European Communities.

Creed, P. A., Kjoelaas, S., \& Hood, M. (2016). Testing a Goal-Orientation Model of Antecedents to Career Calling. Journal of Career Development, 43(5), 398-412. https://doi.org/10.1177/0894845315603822

Dahl, J. (2015). Valuing in ACT. Current Opinion in Psychology, 2, 43-46. https://doi.org/10.1016/j.copsyc.2015.03.001

De Vos, A., Dewettinck, K., \& Buyens, D. (2009). The professional career on the right track: A study on the interaction between career self-management and organizational career management in explaining employee outcomes. European Journal of Work and Organizational Psychology, 18(1), 55-80. https://doi.org/10.1080/13594320801966257

De Vos, A., \& Segers, J. (2013). Self-directed career attitude and retirement intentions. Career Development International, 18(2), 155-172. https://doi.org/10.1108/CDI-04-2012-0041

De Vos, A., Van der Heijden, B. I. J. M., \& Akkermans, J. (2018). Sustainable careers: Towards a conceptual model. Journal of Vocational Behavior. https://doi.org/10.1016/j.jvb.2018.06.011

Duffy, R. D., Blustein, D. L., Diemer, M. A., \& Autin, K. L. (2016). The Psychology of Working Theory. Journal of Counseling Psychology, 63(2), 127-148. https://doi.org/10.1037/cou0000140

Forret, M. L. (2018). Networking as a Job-Search Behavior and Career Management Strategy. In U.-C. Klehe \& E. van Hooft (Eds.), The Oxford Handbook of Job Loss and Job Search. https://doi.org/10.1093/oxfordhb/9780199764921.013.022

Fuller, B., \& Marler, L. E. (2009). Change driven by nature: A meta-analytic review of the proactive personality literature. Journal of Vocational Behavior, 75(3), 329-345. https://doi.org/10.1016/j.jvb.2009.05.008

Ghai, D. (2003). Decent work: Concept and indicators. International Labour Review, 142(2), 113145. https://doi.org/10.1111/j.1564-913X.2003.tb00256.x

Godshalk, V. M., \& Sosik, J. J. (2003). Aiming for career success: The role of learning goal orientation in mentoring relationships. Journal of Vocational Behavior, 63(3), 417-437. https://doi.org/10.1016/S0001-8791(02)00038-6

Gollwitzer, P. M., Mayer, D., Frick, C., \& Oettingen, G. (2018). Promoting the Self-Regulation of Stress in Health Care Providers: An Internet-Based Intervention. Frontiers in Psychology, 9. https://doi.org/10.3389/fpsyg.2018.00838

Gould, S., \& Penley, L. E. (1984). Career strategies and salary progression: A study of their relationships in a municipal bureaucracy. Organizational Behavior and Human Performance, 34(2), 244-265. https://doi.org/10.1016/0030-5073(84)90006-0

Greenhaus, J. H., Callanan, G. A., \& Godshalk, V. M. (2010). Career Management (4th ed.). Sage Publications. 
Greenhaus, J. H., Callanan, G. A., \& Kaplan, E. (1995). The role of goal setting in career management. International Journal of Career Management, 7(5), 3-12. https://doi.org/10.1108/09556219510093285

Gubler, M., Arnold, J., \& Coombs, C. (2014). Organizational boundaries and beyond: A new look at the components of a boundaryless career orientation. Career Development International, 19(6), 641-667. https://doi.org/10.1108/CDI-11-2013-0143

Guthrie, J. P., Coate, C. J., \& Schwoerer, C. E. (1998). Career management strategies: the role of personality. Journal of Managerial Psychology, 13(5/6), 371-386. https://doi.org/10.1108/02683949810220024

Hall, D. T., Yip, J., \& Doiron, K. (2018). Protean Careers at Work: Self-Direction and Values Orientation in Psychological Success. Annual Review of Organizational Psychology and Organizational Behavior, 5(1), 129-156. https://doi.org/10.1146/annurev-orgpsych032117-104631

Hayes, S. C., Luoma, J. B., Bond, F. W., Masuda, A., \& Lillis, J. (2006). Acceptance and Commitment Therapy: Model, processes and outcomes. Behaviour Research and Therapy, 44(1), 1-25. https://doi.org/10.1016/j.brat.2005.06.006

Herrmann, A., Hirschi, A., \& Baruch, Y. (2015). The protean career orientation as predictor of career outcomes: Evaluation of incremental validity and mediation effects. Journal of Vocational Behavior, 88, 205-214. https://doi.org/10.1016/j.jvb.2015.03.008

Heslin, P. A., Keating, L. A., \& Minbashian, A. (2018). How Situational Cues and Mindset Dynamics Shape Personality Effects on Career Outcomes. Journal of Management, 014920631875530. https://doi.org/10.1177/0149206318755302

Hirschi, A. (2012). The career resources model: an integrative framework for career counsellors. British Journal of Guidance \& Counselling, 40(4), 369-383. https://doi.org/10.1080/03069885.2012.700506

Hirschi, A. (2014). Hope as a Resource for Self-Directed Career Management: Investigating Mediating Effects on Proactive Career Behaviors and Life and Job Satisfaction. Journal of Happiness Studies, 15(6), 1495-1512. https://doi.org/10.1007/s10902-013-9488-X

Hirschi, A. (2018). The Fourth Industrial Revolution: Issues and Implications for Career Research and Practice. The Career Development Quarterly, 66(3), 192-204. https://doi.org/10.1002/cdq.12142

Hirschi, A., \& Freund, P. A. (2014). Career Engagement: Investigating Intraindividual Predictors of Weekly Fluctuations in Proactive Career Behaviors. The Career Development Quarterly, 62(1), 5-20. https://doi.org/10.1002/j.2161-0045.2014.00066.x

Hirschi, A., Freund, P. A., \& Herrmann, A. (2013). The Career Engagement Scale: Development and Validation of a Measure of Proactive Career Behaviors. Journal of Career Assessment, 22(4), 1069072713514813-. https://doi.org/10.1177/1069072713514813

Hirschi, A., Lee, B., Porfeli, E. J., \& Vondracek, F. W. (2013). Proactive motivation and engagement in career behaviors: Investigating direct, mediated, and moderated effects. Journal of Vocational Behavior, 83(1), 31-40. https://doi.org/10.1016/j.jvb.2013.02.003

Hirschi, A., Shockley, K. M., \& Zacher, H. (2018). Achieving Work-Family Balance: An Action Regulation Model. Academy of Management Review. https://doi.org/10.5465/amr.2016.0409 
Hooley, T., Watts, A. G., Sultana, R. G., \& Neary, S. (2013). The 'Blueprint' framework for career management skills: a critical exploration. British Journal of Guidance \& Counselling, 41(2), 117-131. https://doi.org/10.1080/03069885.2012.713908

Huang, J.-T., \& Hsieh, H.-H. (2015). Supervisors as good coaches: influences of coaching on employees' in-role behaviors and proactive career behaviors. The International Journal of Human Resource Management, 26(1), 42-58. https://doi.org/10.1080/09585192.2014.940993

International Labour Organization. (2018). The impact of technology on the quality and quantity of jobs (No. 6). International Labor Organization.

Ireland, G. W., \& Lent, R. W. (2018). Career exploration and decision-making learning experiences: A test of the career self-management model. Journal of Vocational Behavior, 106, 37-47. https://doi.org/10.1016/j.jvb.2017.11.004

Jackson, D., \& Wilton, N. (2017a). Career choice status among undergraduates and the influence of career management competencies and perceived employability. Journal of Education and Work, 30(5), 552-569. https://doi.org/10.1080/13639080.2016.1255314

Jackson, D., \& Wilton, N. (2017b). Perceived employability among undergraduates and the importance of career self-management, work experience and individual characteristics. Higher Education Research \& Development, 36(4), 747-762. https://doi.org/10.1080/07294360.2016.1229270

Kanfer, R., \& Ackerman, P. L. (2004). Aging, Adult Development, and Work Motivation. Academy of Management Review, 29(3), 440-458. https://doi.org/10.5465/amr.2004.13670969

Kim, J. G., Kim, H. J., \& Lee, K.-H. (2019). Understanding behavioral job search self-efficacy through the social cognitive lens: A meta-analytic review. Journal of Vocational Behavior. https://doi.org/10.1016/j.jvb.2019.01.004

King, Z. (2004). Career self-management: Its nature, causes and consequences. Journal of Vocational Behavior, 65(1), 112-133. https://doi.org/10.1016/S0001-8791(03)00052-6

Kossek, E. E., Roberts, K., Fisher, S., \& Demarr, B. (1998). Career self-management: A quasiexperimental assessment of the effects of a training intervention. Personnel Psychology, 51(4), 935-960. https://doi.org/10.1111/j.1744-6570.1998.tb00746.x

Kossek, E. E., Ruderman, M. N., Braddy, P. W., \& Hannum, K. M. (2012). Work-nonwork boundary management profiles: A person-centered approach (Vol. 81, pp. 112-128). https://doi.org/10.1016/j.jvb.2012.04.003

Kraimer, M. L., Seibert, S. E., Wayne, S. J., Liden, R. C., \& Bravo, J. (2011). Antecedents and outcomes of organizational support for development: The critical role of career opportunities. Journal of Applied Psychology, 96(3), 485-500. https://doi.org/10.1037/a0021452

Lent, R. W. (2018). Future of Work in the Digital World: Preparing for Instability and Opportunity. The Career Development Quarterly, 66(3), 205-219. https://doi.org/10.1002/cdq.12143

Lent, R. W., Ezeofor, I., Morrison, M. A., Penn, L. T., \& Ireland, G. W. (2016). Applying the social cognitive model of career self-management to career exploration and decision-making. Journal of Vocational Behavior, 93, 47-57. https://doi.org/10.1016/j.jvb.2015.12.007

Lent, R. W., Ireland, G. W., Penn, L. T., Morris, T. R., \& Sappington, R. (2017). Sources of selfefficacy and outcome expectations for career exploration and decision-making: A test of 
the social cognitive model of career self-management. Journal of Vocational Behavior, 99, 107-117. https://doi.org/10.1016/j.jvb.2017.01.002

Lent, R. W., Morris, T. R., Penn, L. T., \& Ireland, G. W. (2018). Social-cognitive predictors of career exploration and decision-making: Longitudinal test of the career self-management model. Journal of Counseling Psychology. https://doi.org/10.1037/cou0000307

Lim, R. H., Lent, R. W., \& Penn, L. T. (2016). Prediction of job search intentions and behaviors: Testing the social cognitive model of career self-management. Journal of Counseling Psychology, 63(5), 594-603. https://doi.org/10.1037/cou0000154

Lord, R. G., Diefendorff, J. M., Schmidt, A. M., \& Hall, R. J. (2009). Self-Regulation at Work. Annual Review of Psychology, 61(1), 543-568. https://doi.org/10.1146/annurev.psych.093008.100314

Maglio, S. J., Gollwitzer, P. M., \& Oettingen, G. (2014). Emotion and control in the planning of goals. Motivation and Emotion, 38(5), 620-634. https://doi.org/10.1007/s11031-014-94074

Mihail, D. M. (2008). Graduates' career orientations and strategies in corporate Greece. Personnel Review, 37(4), 393-411. https://doi.org/10.1108/00483480810877570

Moon, J. S., \& Choi, S. B. (2017). The Impact of Career Management on Organizational Commitment and the Mediating Role of Subjective Career Success: The Case of Korean R\&D Employees. Journal of Career Development, 44(3), 191-208. https://doi.org/10.1177/0894845316643829

Nabi, G. R. (1999). An investigation into the differential profile of predictors of objective and subjective career success. Career Development International, 4(4), 212-225. https://doi.org/10.1108/13620439910270599

Ng, T. W. H., Eby, L. T., Sorensen, K. L., \& Feldman, D. C. (2005). Predictors of objective and subjective career success: A meta-analysis. Personnel Psychology, 58(2), 367-408. https://doi.org/10.1111/j.1744-6570.2005.00515.x

Ng, T. W. H., \& Feldman, D. C. (2014). Subjective career success: A meta-analytic review. Journal of Vocational Behavior, 85(2), 169-179. https://doi.org/10.1016/j.jvb.2014.06.001

Ng, T. W. H., Sorensen, K. L., \& Eby, L. T. (2006). Locus of control at work: a meta-analysis. Journal of Organizational Behavior, 27(8), 1057-1087. https://doi.org/10.1002/job.416

Ng, T. W. H., Sorensen, K. L., Eby, L. T., \& Feldman, D. C. (2007). Determinants of job mobility: A theoretical integration and extension. Journal of Occupational and Organizational Psychology, 80(3), 363-386. https://doi.org/10.1348/096317906X130582

Noe, R. A. (1996). Is career management related to employee development and performance? Journal of Organizational Behavior, 17(2), 119-133. https://doi.org/10.1002/(SICI)10991379(199603)17:2<119::AID-JOB736>3.0.CO;2-O

Oettingen, G., Schnetter, K., \& Pak, H. J. (2001). Self-regulation of goal setting: Turning free fantasies about the future into binding goals. Journal of Personality and Social Psychology, 80(5), 736-753. https://doi.org/10.1037//0022-3514.80.5.736

Ok, A. B., \& Vandenberghe, C. (2016). Organizational and career-oriented commitment and employee development behaviors. Journal of Managerial Psychology, 31(5), 930-945. https://doi.org/10.1108/JMP-04-2015-0157 
Okay-Somerville, B., \& Scholarios, D. (2017). Position, possession or process? Understanding objective and subjective employability during university-to-work transitions. Studies in Higher Education, 42(7), 1275-1291. https://doi.org/10.1080/03075079.2015.1091813

Otto, K., Dette-Hagenmeyer, D. E., \& Dalbert, C. (2010). Occupational Mobility in Members of the Labor Force: Explaining the Willingness to Change Occupations. Journal of Career Development, 36(3), 262-288. https://doi.org/10.1177/0894845309345842

Parker, S. K., Bindl, U. K., \& Strauss, K. (2010). Making Things Happen: A Model of Proactive Motivation. Journal of Management, 36(4), 827-856. https://doi.org/10.1177/0149206310363732

Porath, C., Spreitzer, G., Gibson, C., \& Garnett, F. G. (2012). Thriving at work: Toward its measurement, construct validation, and theoretical refinement. Journal of Organizational Behavior, 33(2), 250-275. https://doi.org/10.1002/job.756

Praskova, A., Creed, P. A., \& Hood, M. (2015). Self-Regulatory Processes Mediating Between Career Calling and Perceived Employability and Life Satisfaction in Emerging Adults. Journal of Career Development, 42(2), 86-101. https://doi.org/10.1177/0894845314541517

Quigley, N. R., \& Tymon, W. G. (2006). Toward an integrated model of intrinsic motivation and career self-management. Career Development International, 11(6), 522-543. https://doi.org/10.1108/13620430610692935

Raabe, B., Frese, M., \& Beehr, T. A. (2007). Action regulation theory and career self-management. Journal of Vocational Behavior, 70(2), 297-311. https://doi.org/10.1016/j.jvb.2006.10.005

Ryan, R. M., \& Deci, E. L. (2000). Self-Determination Theory and the Facilitation of Intrinsic Motivation, Social Development, and Well-Being. American Psychologist, 11.

Schwarzer, R. (2008). Modeling Health Behavior Change: How to Predict and Modify the Adoption and Maintenance of Health Behaviors. Applied Psychology, 57(1), 1-29. https://doi.org/10.1111/j.1464-0597.2007.00325.x

Seibert, S. E., Kraimer, M. L., \& Crant, J. M. (2001). What do proactive people do? A longitudinal model linking proactive personality and career success. Personnel Psychology, 54(4), 845874. https://doi.org/10.1111/j.1744-6570.2001.tb00234.x

Sheldon, K. M. (2014). Becoming Oneself: The Central Role of Self-Concordant Goal Selection. Personality and Social Psychology Review, 18(4), 349-365. https://doi.org/10.1177/1088868314538549

Sheldon, K. M., Kasser, T., Smith, K., \& Share, T. (2002). Personal Goals and Psychological Growth: Testing an Intervention to Enhance Goal Attainment and Personality Integration. Journal of Personality, 70(1), 5-31. https://doi.org/10.1111/1467-6494.00176

Shoss, M. K., Jiang, L., Jundt, D., Lavigne, K., \& Probst, T. (2017). Job Insecurity: An Integrative Review and Agenda for Future Research. Journal of Management, 43(6), 1911-1939. https://doi.org/10.1177/0149206317691574

Singh, R., Ragins, B. R., \& Tharenou, P. (2009). Who gets a mentor? A longitudinal assessment of the rising star hypothesis. Journal of Vocational Behavior, 74(1), 11-17. https://doi.org/10.1016/j.jvb.2008.09.009

Smale, A., Bagdadli, S., Cotton, R., Dello Russo, S., Dickmann, M., Dysvik, A., .. Cross-Cultural Collaboration on Contemporary Careers (5C) research collaborative. (2018). Proactive 
career behaviors and subjective career success: The moderating role of national culture. Journal of Organizational Behavior. https://doi.org/10.1002/job.2316

Spreitzer, G. M., Cameron, L., \& Garrett, L. (2017). Alternative Work Arrangements: Two Images of the New World of Work. Annual Review of Organizational Psychology and Organizational Behavior, 4(1), 473-499. https://doi.org/10.1146/annurev-orgpsych032516-113332

Spurk, D., Hirschi, A., \& Dries, N. (2018). Antecedents and Outcomes of Objective Versus Subjective Career Success: Competing Perspectives and Future Directions. Journal of Management, 014920631878656 . https://doi.org/10.1177/0149206318786563

Strauss, K., Griffin, M. A., \& Parker, S. K. (2012). Future work selves: How salient hoped-for identities motivate proactive career behaviors. Journal of Applied Psychology, 97(3), 580598. https://doi.org/sch

Strauss, K., Parker, S. K., \& O'Shea, D. (2017). When does proactivity have a cost? Motivation at work moderates the effects of proactive work behavior on employee job strain. Journal of Vocational Behavior, 100, 15-26. https://doi.org/10.1016/j.jvb.2017.02.001

Stumpf, S. A., Colarelli, S. M., \& Hartman, K. (1983). Development of the Career Exploration Survey (CES). Journal of Vocational Behavior, 22(2), 191-226. https://doi.org/10.1016/0001-8791(83)90028-3

Sturges, J. (2008). All in a day's work? Career self-management and the management of the boundary between work and non-work. Human Resource Management Journal, 18(2), 118-134. https://doi.org/10.1111/j.1748-8583.2007.00054.x

Sturges, J., Conway, N., Guest, D., \& Liefooghe, A. (2005). Managing the career deal: the psychological contract as a framework for understanding career management, organizational commitment and work behavior. Journal of Organizational Behavior, 26(7), 821-838. https://doi.org/10.1002/job.341

Sturges, J., Conway, N., \& Liefooghe, A. (2008). What's the deal? An exploration of career management behaviour in Iceland. The International Journal of Human Resource Management, 19(4), 752-768. https://doi.org/10.1080/09585190801953814

Sturges, J., Conway, N., \& Liefooghe, A. (2010). Organizational Support, Individual Attributes, and the Practice of Career Self-Management Behavior. Group \& Organization Management, 35(1), 108-141. https://doi.org/10.1177/1059601109354837

Sturges, J., Guest, D., Conway, N., \& Davey, K. M. (2002). A longitudinal study of the relationship between career management and organizational commitment among graduates in the first ten years at work. Journal of Organizational Behavior, 23(6), 731-748. https://doi.org/10.1002/job.164

Taber, B. J., \& Blankemeyer, M. (2015). Future work self and career adaptability in the prediction of proactive career behaviors. Journal of Vocational Behavior, 86, 20-27. https://doi.org/10.1016/j.jvb.2014.10.005

Tharenou, P., \& Terry, D. J. (1998). Reliability and Validity of Scores on Scales to Measure Managerlal Aspirations. Educational and Psychological Measurement, 58(3), 475-492. https://doi.org/10.1177/0013164498058003008

Tharmaseelan, N., Inkson, K., \& Carr, S. C. (2010). Migration and career success: testing a timesequenced model. Career Development International, 15(3), 218-238. https://doi.org/10.1108/13620431011053712 
Thomas, J. P., Whitman, D. S., \& Viswesvaran, C. (2010). Employee proactivity in organizations: A comparative meta-analysis of emergent proactive constructs. Journal of Occupational and Organizational Psychology, 83(2), 275-300. https://doi.org/10.1348/096317910X502359

Tims, M., Bakker, A. B., \& Derks, D. (2012). Development and validation of the job crafting scale. Journal of Vocational Behavior, 80(1), 173-186. https://doi.org/10.1016/j.jvb.2011.05.009

Vittersø, J. (2013). Functional Well-being: Happiness as Feelings, Evaluations, and Functioning. In I. Boniwell, S. A. David, \& A. C. Ayers (Eds.), Oxford Handbook of Happiness (pp. 227-246). Oxford University Press.

Vos, A., Clippeleer, I., \& Dewilde, T. (2009). Proactive career behaviours and career success during the early career. Journal of Occupational and Organizational Psychology, 82(4), 761-777. https://doi.org/10.1348/096317909X471013

Wiernik, B. M., \& Kostal, J. W. (in press). Protean and Boundaryless Career Orientations: A Critical Review and Meta-Analysis. Journal of Counseling Psychology, 34.

Wolff, H.-G., Schneider-Rahm, C. I., \& Forret, M. L. (2011). Adaptation of a German Multidimensional Networking Scale into English. European Journal of Psychological Assessment, 27(4), 244-250. https://doi.org/10.1027/1015-5759/a000070

World Economic Forum. (2018). The Future of Jobs Report 2018. Retrieved from https://www.weforum.org/reports/the-future-of-jobs-report-2018

Zacher, H., Schmitt, A., Jimmieson, N. L., \& Rudolph, C. W. (2018). Dynamic effects of personal initiative on engagement and exhaustion: The role of mood, autonomy, and support. Journal of Organizational Behavior. https://doi.org/10.1002/job.2277

Zikic, J., \& Klehe, U.-C. (2006). Job loss as a blessing in disguise: The role of career exploration and career planning in predicting reemployment quality. Journal of Vocational Behavior, 69(3), 391-409. https://doi.org/10.1016/j.jvb.2006.05.007 
Tables

Table 1

Overview of CSM behavior classification

\begin{tabular}{|c|c|c|}
\hline Direction of behavior & Examples of behaviors & Scale examples \\
\hline \multicolumn{3}{|l|}{ Directed at self } \\
\hline \multirow{5}{*}{$\begin{array}{l}\text { Applies, maintains or develops personal } \\
\text { resources, such as knowledge, human capital, } \\
\text { or position }\end{array}$} & Self-exploration & $\begin{array}{l}\text { Stumpf, Colarelli, \& Hartmann } \\
\text { (1983) }\end{array}$ \\
\hline & Environmental exploration & Stumpf et al. (1983) \\
\hline & Learning, investment in human capital & $\begin{array}{l}\text { Gould \& Penley (1984); Hirschi et } \\
\text { al. (2018) }\end{array}$ \\
\hline & Job crafting & Tims, Bakker, \& Derks (2012) \\
\hline & Self-initiated mobility behavior & $\begin{array}{l}\text { Otto, Dette-Hagenmeyer, \& Dalbert } \\
\text { (2010); Gubler, Arnold, \& Coombs } \\
\text { (2014); Sturges et al. (2008) }\end{array}$ \\
\hline \multicolumn{3}{|l|}{ Directed at context } \\
\hline \multirow{2}{*}{$\begin{array}{l}\text { Applies, maintains, or develops contextual } \\
\text { resources such as social capital, influence, or } \\
\text { mentorship }\end{array}$} & Self-promotion, creating visibility & $\begin{array}{l}\text { Gould \& Penley (1984); Sturges et } \\
\text { al. (2002) }\end{array}$ \\
\hline & Networking & $\begin{array}{l}\text { Wolff, Schneider-Rahm, \& Forret } \\
\text { (2011) }\end{array}$ \\
\hline
\end{tabular}




\begin{tabular}{lll}
\hline Direction of behavior & Examples of behaviors & Scale examples \\
\hline & Guidance and feedback seeking & $\begin{array}{l}\text { Gould \& Penley (1984); Claes \& } \\
\text { Ruiz-Quintanilla (1998) }\end{array}$ \\
& Influencing others & Gould \& Penley (1984) \\
& & Gould (1979); Claes \& Ruiz- \\
$\begin{array}{l}\text { Directed at regulation of CSM processes } \\
\text { regulates process of CSM and the relation } \\
\text { between multiple life roles }\end{array}$ & Goal setting, planning, and monitoring & Kossek, Ruderman, Braddy, \& \\
& & Hannum (2012)
\end{tabular}




\section{Figures}

\begin{tabular}{|l|}
\hline Personal Antecedents \\
Personality traits \\
- Big Five \\
- Functional constructs \\
Motivational states \\
- Can do (e.g., self-efficacy) \\
- Reason to (e.g., protean career \\
$\quad$ orientation) \\
- Energized to (e.g., positive \\
affect) \\
Contextual Antecedents \\
Social support \\
Barriers \\
Macro-context
\end{tabular}

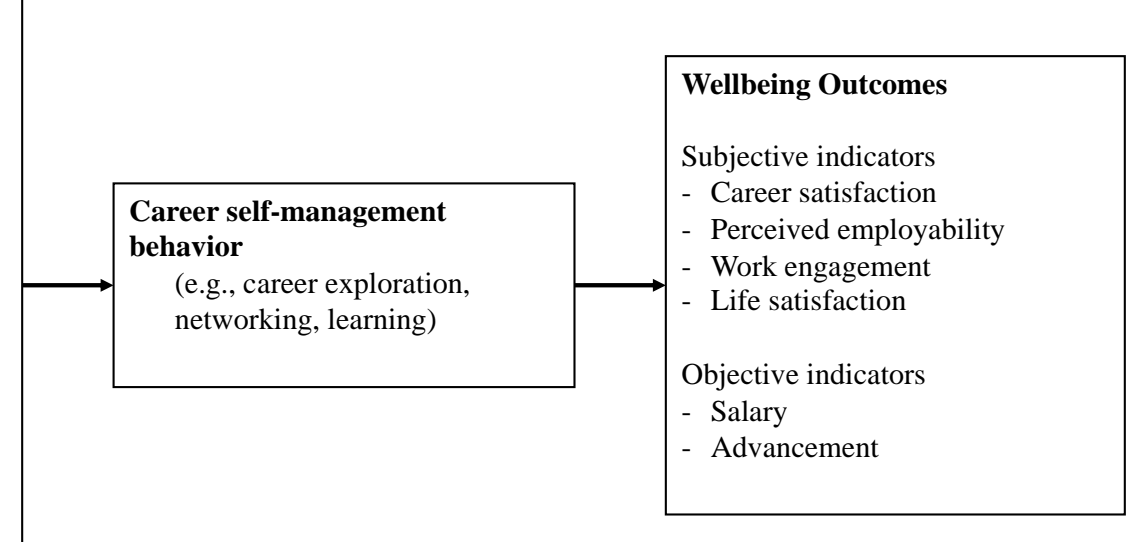

Figure 1. Overview of reviewed constructs in this chapter. 